\title{
Rapid inactivation of SARS-CoV-2 by titanium dioxide surface
}

\section{coating [version 1; peer review: 2 approved with reservations]}

\author{
Petra Micochova ${ }^{1}$, Ambika Chadha2 ${ }^{2}$ Timi Hesseloj3,4, Franca Fraternali4,5, \\ Jeremy J. Ramsden6, Ravindra K. Gupta (D) 1,2
}

${ }^{1}$ Cambridge Institute of Therapeutic Immunology \& Infectious Disease (CITIID), University of Cambridge, Cambridge, UK

2University of Cambridge Addenbrooke's Hospital Cambridge, Cambridge, UK

3Invisismart Technologies, London, UK

${ }^{4}$ Randall Centre for Cell and Molecular Biophysics, King's College London, London, UK

${ }^{5}$ Development and Homeostasis of the Nervous System Laboratory, The Francis Crick Institute, London, UK

${ }^{6}$ Clore Laboratory, University of Buckingham, Buckingham, UK

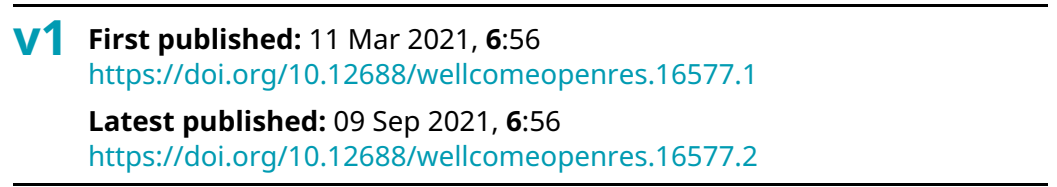

\section{Abstract}

Background: Severe acute respiratory syndrome coronavirus 2 (SARSCoV-2) transmission occurs via airborne droplets and surface contamination. Titanium dioxide $\left(\mathrm{TiO}_{2}\right)$ coating of surfaces is a promising infection control measure, though to date has not been tested against SARS-CoV-2.

Methods: Virus stability was evaluated on $\mathrm{TiO}_{2}$ - and $\mathrm{TiO}_{2}-\mathrm{Ag}$ ( $\mathrm{Ti}: \mathrm{Ag}$ atomic ratio 1:0.04)-coated $45 \times 45 \mathrm{~mm}$ ceramic tiles. After coating the tiles were stored for 2-4 months before use. We tested the stability of both SARS-CoV-2 Spike pseudotyped virions based on a lentiviral system, as well as fully infectious SARS-CoV-2 virus. For the former, tile surfaces were inoculated with SARS-CoV-2 spike pseudotyped HIV-1 luciferase virus. At intervals virus was recovered from surfaces and target cells infected. For live virus, after illuminating tiles for 0-300 min virus was recovered from surfaces followed by infection of Vero E6 cells. \% of infected cells was determined by flow cytometry detecting SARS-CoV-2 nucleocapsid protein $24 \mathrm{~h}$ post-infection. Results: After $1 \mathrm{~h}$ illumination the pseudotyped viral titre was decreased by four orders of magnitude. There was no significant difference between the $\mathrm{TiO}_{2}$ and $\mathrm{TiO}_{2}$-Ag coatings. Light alone had no significant effect on viral viability. For live SARS-CoV-2, virus was already significantly inactivated on the $\mathrm{TiO}_{2}$ surfaces after 20 min illumination. After $5 \mathrm{~h}$ no detectable active virus remained.

Significantly, SARS-CoV-2 on the untreated surface was still fully infectious at $5 \mathrm{~h}$ post-addition of virus. Overall, tiles coated with $\mathrm{TiO}_{2}$ 120 days previously were able to inactivate SARS-CoV-2 under ambient indoor lighting with $87 \%$ reduction in titres at $1 \mathrm{~h}$ and complete loss by 5h exposure.

Conclusions: In the context of emerging viral variants with increased transmissibility, $\mathrm{TiO}_{2}$ coatings could be an important tool in containing

\section{Open Peer Review}

Approval Status

1

2

version 2

(revision)

09 Sep 2021

version 1

11 Mar 2021

$\checkmark$
view
$?$
$?$
view

view
$?$
view

1. Gert U. van Zyl (D), Tygerberg Hospital, Cape Town, South Africa

Stellenbosch University, Stellenbosch, South

Africa

2. Xuan Xue ID, University of Nottingham,

Nottingham, UK

Any reports and responses or comments on the article can be found at the end of the article. 
SARS-CoV-2, particularly in health care facilities where nosocomial infection rates are high.

Keywords

Surface, SARS-CoV-2, coating, spray, TiO2

Corresponding author: Ravindra K. Gupta (rkg20@cam.ac.uk)

Author roles: Micochova P: Conceptualization, Investigation, Methodology, Writing - Original Draft Preparation; Chadha A:

Conceptualization, Funding Acquisition, Project Administration; Hesseloj T: Conceptualization, Project Administration, Writing - Original Draft Preparation, Writing - Review \& Editing; Fraternali F: Conceptualization, Writing - Review \& Editing; Ramsden JJ:

Conceptualization, Formal Analysis, Investigation, Methodology, Writing - Original Draft Preparation, Writing - Review \& Editing; Gupta RK: Conceptualization, Funding Acquisition, Writing - Review \& Editing

Competing interests: TH is chief scientific officer of Invisi Smart Technologies. JJR has consulted for Invisi Smart Technologies. RKG has received a research grant from Invisi Smart Technologies.

Grant information: This work was supported by the Wellcome Trust through a Senior Clinical Research Fellowship to RKG [108082, https://doi.org/10.35802/108082]. This work was also supported by Invisi Smart Technologies.

Copyright: @ 2021 Micochova P et al. This is an open access article distributed under the terms of the Creative Commons Attribution License, which permits unrestricted use, distribution, and reproduction in any medium, provided the original work is properly cited.

How to cite this article: Micochova $\mathrm{P}$, Chadha $A$, Hesseloj T et al. Rapid inactivation of SARS-CoV-2 by titanium dioxide surface coating [version 1; peer review: 2 approved with reservations] Wellcome Open Research 2021, 6:56 https://doi.org/10.12688/wellcomeopenres.16577.1

First published: 11 Mar 2021, 6:56 https://doi.org/10.12688/wellcomeopenres.16577.1 


\section{Background}

Respiratory droplets are believed to be the major vehicle of severe acute respiratory syndrome coronavirus 2 (SARS-CoV-2) transmission. Droplets or other body fluids from infected individuals can contaminate surfaces and viable virus has been detected on such surfaces, including surgical masks, for hours, even days depending on different factors including humidity, temperature and type of surface ${ }^{1-3}$. One therefore infers that any external contamination of personal protective equipment (PPE) may last hours or even days.

Recently, there has been a further increase in SARS-CoV-2 cases globally, despite severe mitigation measures following the first wave in the first half of 2020. The new UK, Brazilian and South African variants (501Y.V1/V2/V3) have led to global anxiety and high levels of nosocomial transmission within hospitals are being observed in the 2020/21 UK winter despite universal adoption of wearing face masks, regular testing of staff and patients, and social distancing measures. It may well be that contamination of surfaces is now disproportionately contributing to transmission ${ }^{4,5}$.

Traditional forms of decontamination (such as alcohol-based sprays, quaternary ammonium compounds, and sodium hypochlorite and other chlorine-based compounds) require repeated applications. Photocatalytic surfaces, on the other hand, permanently oxidize, inactivate and destroy microorganisms under normal ambient lighting conditions ${ }^{6}$. A recent hospital study of titanium dioxide-coated surfaces demonstrated progressive lowering of the bacterial bioburden ${ }^{7}$. Moreover, the radicals are not considered to induce antimicrobial resistance ${ }^{8}$. $\mathrm{TiO}_{2}$ is especially attractive because it is considered nontoxic to humans: titanium, coated with its oxide, is the most widely used material for implants ${ }^{9}$. $\mathrm{TiO}_{2}$ is also exceedingly stable, unlike other photocatalysts such as zinc oxide and tungsten trioxide. Illumination of $\mathrm{TiO}_{2}$ generates highly oxidizing free radicals that are known to have bactericidal and antiviral action against influenza and rotavirus ${ }^{10-12}$. SARS-CoV-2 has not hitherto been investigated.

\section{Methods}

Cell lines

293T and Vero E6 cells were cultured in DMEM complete (DMEM, Sigma D5030) supplemented with $100 \mathrm{U} / \mathrm{ml}$ penicillin (Sigma), $0.1 \mathrm{mg} / \mathrm{ml}$ streptomycin (Sigma), and $10 \%$ fetal calf serum, GIBCO, Thermofisher). Vero E6 were a gift from Prof. Ian Goodfellow. 293T cells were a gift from Prof Greg Towers. ACE-2/TMPRSS2-expressing 293T cells were generated by transfecting plasmids expressing ACE-2/TMPRSS2 from a CMV promoter in pCDNA3.1 (Thermofisher Cat no: V79020) ${ }^{13}$

\section{Pseudotyped virus}

SARS-CoV-2 Spike pseudotyped HIV-1 luciferase particles were produced by transfection of $293 \mathrm{~T}$ cells with 1ug pCAGGSSARS-CoV-2 Spike expressing plasmid (NIBSC cat no: 100976), lug p8.91HIV-1 gag-pol expression plasmid (a gift from Prof Greg Towers) and 1.5ug pCSFLW (expressing the firefly luciferase reporter gene with the HIV-1 packaging signal - a gift from Prof Greg Towers) $)^{14}$. Plasmids were mixed in Optimem (GIBCO, Thermofisher Cat no: 31985062)) Following transfection in $10 \mathrm{~cm}$ plastic petri dishes (Nunc cat no:150464), viral supernatant was collected at 48 and $72 \mathrm{~h}$ after transfection, filtered through a $0.45 \mu \mathrm{m}$ filter (Millipore, cat no: HAWP04700) and stored at $-80{ }^{\circ} \mathrm{C}$. The $50 \%$ tissue culture infectious dose $\left(\right.$ TCID $\left._{50}\right)$ of SARS-CoV-2 pseudovirus was determined using the Steady-Glo luciferase (Promega cat no: E2550) assay system including a luminometer (Glomax Navigator Luminometer, Promega, cat no: GM2000).

\section{Viral isolate}

Live SARS-CoV-2 (SARS-CoV-2/human/Liverpool/ REMRQ0001/2020) used in this study was isolated by Lance Turtle (University of Liverpool), David Matthews and Andrew Davidson (University of Bristol). A SARS-CoV-2 virus stock was produced by infecting Vero E6 cells at MOI 0.01. Culture supernatant was collected $48 \mathrm{~h}$ post-infection. The titre of the stock was determined by adding tenfold serial dilutions of virus onto Vero E6 cells. 24 h post-infection cells were fixed by removing media and replacing with $3 \%$ paraformaldehyde in PBS. Samples were stained for nucleocapsid protein using a monoclonal rabbit anti-Nucleocapsid antibody $(1: 1000$, MA5-36086, ThermoFisher) and \% infection determined by flow cytometry on a BD FACSCalibur instrument, with 10,000 cells were counted. SARS-CoV-2 virus titres were determined as infectious units per $\mathrm{ml}$ (IU/ml) as follows: $(\%$ infected cells $) \times($ total number of cells $) \times($ dilution factor $) /$ volume of inoculum added to cells.

\section{Surfaces and illumination}

Ceramic tiles were wiped down with neutral disinfectant then coated with either a $\mathrm{TiO} 2$ based solution or with a combination of $\mathrm{TiO} 2$ and $\mathrm{Ag}$ using a spray gun (bespoke). The tiles were allowed to dry for 15 minutes. The spray gun was connected to an $11 \mathrm{~L}$ air compressor (Makita). The nozzle orifice was 8 microns with pressure fixed at 12 PSI to atomise the coating. Virus stability was evaluated on the following surfaces: sterile untreated Sterilin standard Petri dish; $\mathrm{TiO}_{2}$ and $\mathrm{TiO}_{2}-\mathrm{Ag}$ (Ti:Ag atomic ratio 1:0.04)-coated $45 \times 45 \mathrm{~mm}$ ceramic tiles (Invisi Smart Technologies UK Ltd). The coatings are transparent and colourless and therefore invisible to the human eye. After coating the tiles were stored for 2-4 months before use. Surfaces were exposed (610 lx, ambient laboratory light) for $1 \mathrm{~h}$ before the start of each experiment to ensure a steady state of radical generation. The same light was used during virus exposure, during which relative humidity was approximately $65 \%$ and temperature $21{ }^{\circ} \mathrm{C}$ (in a microbiological safety cabinet).

\section{Surface inoculation and sampling}

SARS-CoV-2 spike pseudotyped virus inactivation. Tile surfaces were inoculated with $10^{5}$ RLU of SARS-CoV-2 spike pseudotyped HIV-1 luciferase virus at time $t=0$ and illuminated for up to $6 \mathrm{~h}$. At intervals virus was recovered from surfaces with DMEM complete followed by infection of ACE-2/ TMPRSS2-expressing $293 \mathrm{~T}$ cells. Luminescence was measured using Steady-Glo Luciferase assay system (Promega) $48 \mathrm{~h}$ post-infection. 
SARS-CoV-2 live virus inactivation. $6 \times 10^{6} \mathrm{IU} / \mathrm{ml}$ of SARSCoV-2 virus was added onto the surface of the tiles at a dosage of $2 \mu \mathrm{l}$ over $5 \times 5 \mathrm{~mm}$. After illuminating for $0-300 \mathrm{~min}$ virus was recovered from surfaces with DMEM complete followed by infection of Vero E6 cells. \% of infected cells was determined by flow cytometry detecting SARS-CoV-2 nucleocapsid protein $24 \mathrm{~h}$ post-infection.

\section{Kinetic analysis of inactivation}

The main challenge is that laboratory inactivation experiments are necessarily carried out with large numbers of viruses, with which the inactivating material is brought into contact at the beginning of the experiment, and the decay of the entire virus population is measured ${ }^{15}$. What is of practical interest in the scenario of a coating designed to keep surfaces (e.g., in a hospital) free of viral (and bacterial) bioburden is how quickly an individual virus is inactivated. According to analysis of previously reported results for influenza virus inactivation $^{11}$, the kinetics fit a convective diffusion transport model even in the absence of mechanical agitation, most likely due to almost inevitable thermal gradients ${ }^{15}$. The concentration of survivors is thereby predicted to follow a so-called exponential decrease, and plotting the logarithm of the number of survivors v. time should give a straight line, the slope of which is $-k$, the inactivation rate coefficient. The value of $k$ can then be compared with the transport-limited fastest possible rate calculated from the size of the virus ${ }^{15}$.

\section{Statistical analysis}

We did not perform statistical analyses in this work.

\section{Results}

After $1 \mathrm{~h}$ illumination the pseudotyped viral titre was decreased by four orders of magnitude (Figure $1 \mathrm{~A}^{16}$ ). There was no significant difference between the $\mathrm{TiO}_{2}$ and $\mathrm{TiO}_{2}-\mathrm{Ag}$ coatings. Light alone had no significant effect on viral viability.
A

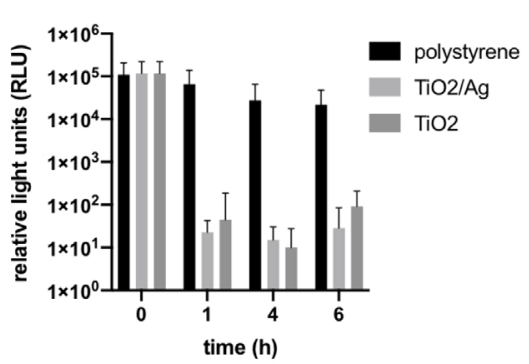

B

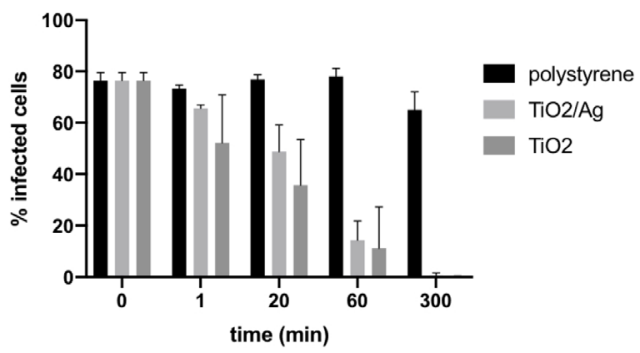

C

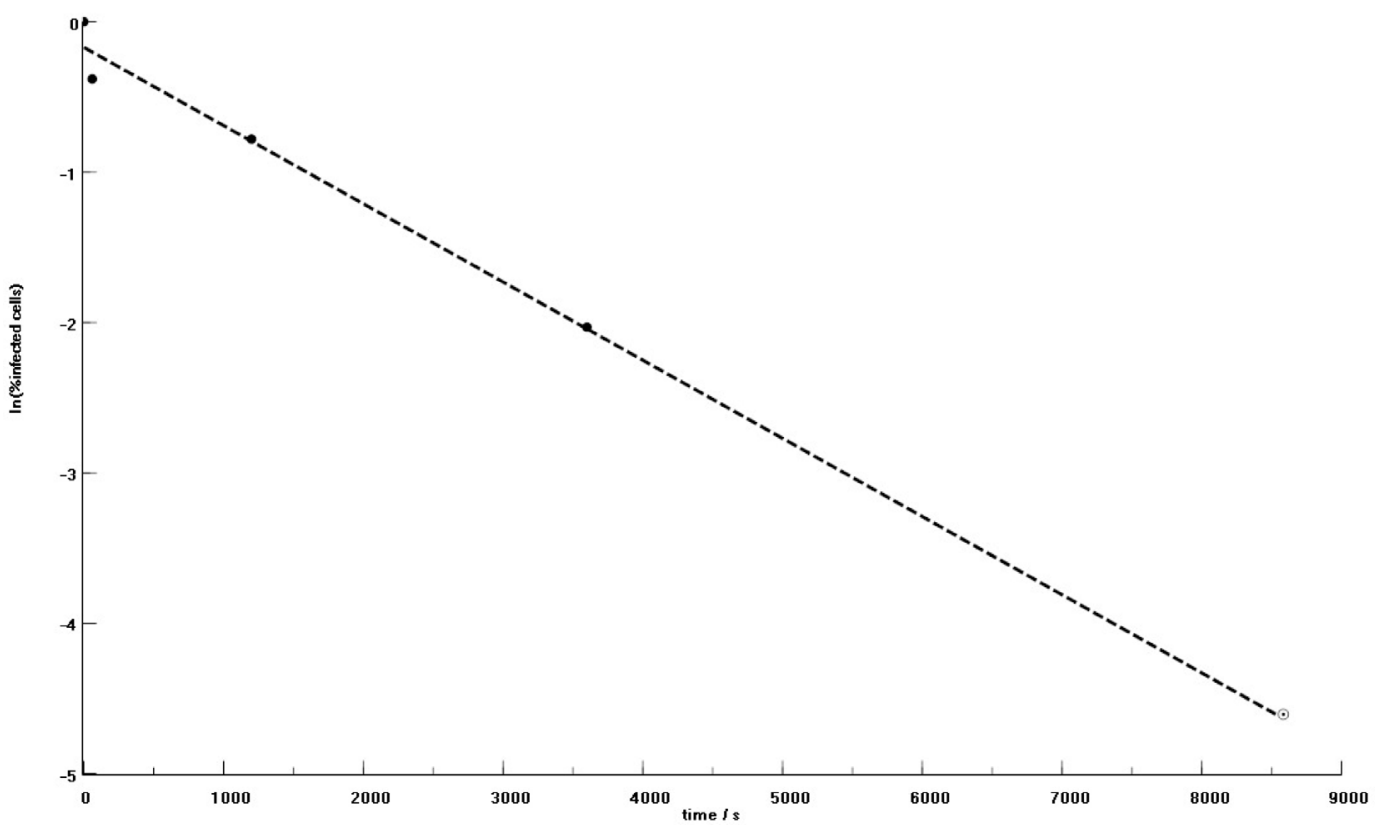

Figure 1. Effect of $\mathrm{TiO}_{2} / \mathbf{A g}$ and $\mathrm{TiO}_{2}$ coated tiles on. (A) SARS-CoV-2 Spike pseudotype viral infection and (B) SARS-CoV-2 isolate REMRQ0001/Human/2020/Liverpool (C) Plot of the experimental data from (B) as In(\%infected cells) v. time (s). Dashed line represents a linear regression using the first 4 data points. The slope of the line yields a disinfection rate coefficient $k$. 
Next, we tested the ability of the coated tiles to inhibit fully infectious live virus. Coated and uncoated surfaces were exposed to SARS-CoV-2. Virus was harvested at the times indicated and used to infect Vero E6 target cells. SARS-CoV-2 was already significantly inactivated on the $\mathrm{TiO}_{2}$ surfaces after 20 min illumination. After $5 \mathrm{~h}$ no detectable active virus remained (Figure $1 \mathrm{~B}^{16}$ ). Significantly, SARS-CoV-2 on the untreated surface was still fully infectious at $5 \mathrm{~h}$ post-addition of virus. $\mathrm{TiO}_{2}-\mathrm{Ag}$ appeared somewhat less effective than $\mathrm{TiO}_{2}$ alone, but the difference was not significant.

Plotting the experimental data (Figure $1 \mathrm{~B}^{16}$ ) as $\ln ($ titre) v. time (Figure $1 \mathrm{C}^{16}$ ) yields a disinfection rate coefficient $k$ of $(5.2 \pm 0.6) \times 10^{-4} \mathrm{~s}^{-1}$, which corresponds to the transport-limited fastest possible rate estimated for SARS-CoV-2 approaching a disinfecting surface in water ${ }^{15}$. Hence we infer that the viruses arriving at the surface from the inoculum are essentially immediately inactivated. From our illumination conditions we estimate the generation rate of radicals as about $10^{13} \mathrm{~cm}^{-2} \mathrm{~s}^{-1}$, corresponding to about 800 radicals $\mathrm{s}^{-1}$ over the area occupied by one virus at the surface, By extrapolating the data from the first four points to the assumed detection limit, it can be seen that very likely no detectable virus from the initial inoculum remained soon after $2 \mathrm{~h}$ exposure (Figure $1 \mathrm{C}^{16}$ ).

\section{Discussion}

The potent extended anti- SARS-CoV-2 effect of titanium dioxide surface coatings is highly desirable in hospital settings where both patients and staff might be shedding viruses. An important advantage of these surfaces is that they can be activated by ordinary interior light and do not need UV irradiation, which is usually incompatible with simultaneous human presence. The coating has a rough surface with high local curvature that creates an absorption tail into the blue region of the visible spectrum ${ }^{6}$, overlapping the spectral output of ordinary interior lighting. This is sufficient to ensure an adequate rate of radical generation for effectively immediately inactivating viruses and other microorganisms arriving from the air or hand touches. Conversely, a limitation is that if a sudden very large contamination event occurred, particularly one that severely diminished the light reaching the photocatalyst, it might take impracticably long for the contamination to be eliminated. Hence, in that case rough cleaning, even washing with water, should be used to remove the gross contamination.

The efficacy of the $\mathrm{TiO}_{2}$ coating under typical hospital lighting makes it a promising candidate for enhancing the protection afforded by facemasks and other PPE, and well as surfaces likely to be contaminated and hence acting as reservoirs for transmitting infection if left untreated. Such interventions are increasingly critical in conditions where viral variants with increased transmissibility are the new norm ${ }^{14,17}$.

\section{Data availability}

Underlying data

DRYAD: SARS-CoV-2 viability after exposure to titanium dioxide coated tiles. https://doi.org/10.5061/dryad.4j0zpc89 $\mathrm{z}^{16}$

This project contains the following underlying data:

- PM_luminometer_data-1.xlsx (Luminometer data for SARS-CoV-2 spike pseudotyped virus inactivation)

- TiO2_fcs files.zip (Flow cytometry data for SARS-CoV-2 live virus inactivation)

Data are available under the terms of the Creative Commons Zero "No rights reserved" data waiver (CCO 1.0 Public domain dedication)

\section{Acknowledgment}

The authors thank Saba Yussouf (Invisi Smart Technologies) for helpful discussions. We would also like to thank Nigel Temperton for the plasmids.
1. Chin AWH, Chu JTS, Perera MRA, et al.: Stability of SARS-CoV-2 in different environmental conditions. Lancet Microbe. 2020; 1(1): e10. PubMed Abstract | Publisher Full Text | Free Full Text

2. van Doremalen $\mathrm{N}$, Bushmaker T, Morris DH, et al:: Aerosol and Surface Stability of SARS-CoV-2 as Compared with SARS-CoV-1. N EnglJ Med. 2020 382(16): 1564-1567.

PubMed Abstract | Publisher Full Text | Free Full Text

3. Chia PY, Coleman KK, Tan YK, et al.: Detection of air and surface contamination by SARS-CoV-2 in hospital rooms of infected patients. Nat Commun. 2020; 11(1): 2800.

PubMed Abstract | Publisher Full Text | Free Full Text

4. Rivett L, Sridhar S, Sparkes D, et al.: Screening of healthcare workers for SARS-CoV-2 highlights the role of asymptomatic carriage in COVID-19 transmission. eLife. 2020; 9: e58728.

PubMed Abstract | Publisher Full Text | Free Full Text

5. Collier DA, Assennato SM, Warne B, et al.: Point of care nucleic acid testing for SARS-CoV-2 in hospitalized patients: A clinical validation trial and implementation study. Cell Rep Med. 2020; 1(5): 100062. PubMed Abstract | Publisher Full Text | Free Full Text

6. Ramsden J: Photocatalytic antimicrobial coatings. Nanotechnol Percept. 2015; 11(3): 146-168 Publisher Full Text

7. Reid M, Whatley V, Spooner E, et al.: How does a photocatalytic antimicrobial coating affect environmental bioburden in hospitals? Infect Control Hosp Epidemiol. 2018; 39(4): 398-404.

PubMed Abstract | Publisher Full Text

8. Ramsden J]: Can bacteria develop resistance to photocatalytically generated reactive oxygen species? J Biol Phys Chem. 2017; 17(2): 47-51. Publisher Full Text

9. Ramsden J]: Biomedical Surfaces. Norwood, MA: Artech House. 2008; 1-25. Reference Source

10. Bonetta S, Bonetta S, Motta F, et al.: Photocatalytic bacterial inactivation by TiO2-coated surfaces. AMB Express. 2013; 3(1): 59. PubMed Abstract | Publisher Full Text | Free Full Text 
11. Nakano $\mathrm{R}$, Ishiguro $\mathrm{H}$, Yao $\mathrm{Y}$, et al.: Photocatalytic inactivation of influenza virus by titanium dioxide thin film. Photochem Photobiol Sci. 2012; 11(8):

$$
\text { 1293-8. }
$$

PubMed Abstract | Publisher Full Text

12. Sang $X$, Phan TG, Sugihara S, et al.: Photocatalytic inactivation of diarrheal viruses by visible-light-catalytic titanium dioxide. Clin Lab. 2007; 53(7-8): 413-21.

PubMed Abstract

13. Mlcochova $P$, Collier D, Ritchie A, et al.: Combined point-of-care nucleic acid and antibody testing for SARS-CoV-2 following emergence of D614G Spike Variant. Cell Rep Med. 2020; 1(6): 100099.

PubMed Abstract | Publisher Full Text | Free Full Text
14. Kemp SA, Harvey WT, Lytras $S$, et al.: Recurrent emergence and transmission of a SARS-CoV-2 Spike deletion H69/V70. bioRxiv. 2021. Publisher Full Text

15. Ramsden Jj: The kinetics of disinfection by semiconductor photocatalysts. J Biol Phys Chem. 2020; 20(2): 60-7.

16. Gupta R, Mlcochova P: SARS-CoV-2 viability after exposure to titanium dioxide coated tiles. Dryad, Dataset, 2021. http://www.doi.org/10.5061/dryad.4j0zpc89z

17. Kemp SA, Collier DA, Datir RP, et al.: SARS-CoV-2 evolution during treatment of chronic infection. Nature. 2021. PubMed Abstract | Publisher Full Text 


\section{Open Peer Review}

\section{Current Peer Review Status: ? ?}

Version 1

Reviewer Report 26 July 2021

https://doi.org/10.21956/wellcomeopenres.18269.r45067

(C) 2021 Xue X. This is an open access peer review report distributed under the terms of the Creative Commons Attribution License, which permits unrestricted use, distribution, and reproduction in any medium, provided the original work is properly cited.

\section{Xuan Xue}

School of Pharmacy, University of Nottingham, Nottingham, UK

In this research article, the authors demonstrated that titanium dioxide $\left(\mathrm{TiO}_{2}\right)$ - and $\mathrm{TiO}_{2}-\mathrm{Ag}$ coating of surfaces can be a promising measure to reduce the fomite transmission of SARS-CoV-2 for future infection protection control. $\mathrm{TiO}_{2}$ has been previously demonstrated to have bactericidal and antiviral action against influenza and rotavirus, but not yet studied on SARS-CoV-2, by generating oxidizing free radicals under light. This research compared the stability of SARS-CoV-2 Spike pseudo virus and infectious SARS-CoV-2 virus on coated and uncoated surfaces, and the results of which evidenced that $\mathrm{TiO}_{2}$ - and $\mathrm{TiO}_{2}-\mathrm{Ag}$ coatings, compared to the uncoated control surfaces, effectively inactivated both SARS-CoV-2 pseudo and live viruses under ambient indoor light within hours. The authors indicated the potential of $\mathrm{TiO}_{2}$ coatings as a tool in contribution to the control of SARS-CoV-2 transmission in public and health care settings. In this manuscript, the work has been well designed, clearly presented and concluded with relative adequate data.

Some minor comments are stated below:

1. There are a few different types of materials, e.g. metal-based, silicon-based, carbon-based, and polymers, that have been showing antiviral potentials. It would be good to briefly review the current literature on them and indicate the merit for investigating more on $\mathrm{TiO}_{2}-$ coatings than others.

2. The coating procedure was described in the methods section without further optimisation. Also, there are no further discussions on the validation and evaluation of the successful coatings on the surface. A series of surface characterisation techniques are therefore recommended, for example, ToF-SIMS and XPS to confirm the surface chemistries and their distributions after coating, and SEM to show the surface features and uniformity of the coating.

3. The virus stability was evaluated on both $\mathrm{TiO}_{2}$ - coated and uncoated (control) surfaces. According to Fig. $1 \mathrm{~B}$, polystyrene surface was used as the control substrate. However, as the coatings were applied on tiles (please specify its material) and no data have evidenced the successful coating (please see Comment 2), an uncoated tile surface would be a more 
appropriate control substrate compared to polystyrene.

4. In order to recommend on effective inactivation of virus on $\mathrm{TiO}_{2}$ - coated surfaces for health care facilities in the future, it would be good to have more details of the light applied in this research as well as investigate more on different lights, in terms of their type, power, and applied distance to surfaces, in this study.

Is the work clearly and accurately presented and does it cite the current literature? Partly

Is the study design appropriate and is the work technically sound?

Yes

Are sufficient details of methods and analysis provided to allow replication by others? Partly

If applicable, is the statistical analysis and its interpretation appropriate? Not applicable

Are all the source data underlying the results available to ensure full reproducibility? Partly

Are the conclusions drawn adequately supported by the results? Yes

Competing Interests: No competing interests were disclosed.

Reviewer Expertise: Antiviral materials, surface chemistry, polymer chemistry, biomaterials, high throughput screening

I confirm that I have read this submission and believe that I have an appropriate level of expertise to confirm that it is of an acceptable scientific standard, however I have significant reservations, as outlined above.

Author Response 07 Sep 2021

Ravindra Gupta, University of Cambridge, Cambridge, UK

Reviewer 2:

In this research article, the authors demonstrated that titanium dioxide $\left(\mathrm{TiO}_{2}\right)$ - and $\mathrm{TiO}_{2}-\mathrm{Ag}$ coating of surfaces can be a promising measure to reduce the fomite transmission of SARS$\mathrm{CoV}-2$ for future infection protection control. $\mathrm{TiO}_{2}$ has been previously demonstrated to have bactericidal and antiviral action against influenza and rotavirus, but not yet studied on SARS-CoV-2, by generating oxidizing free radicals under light. This research compared the stability of SARS-CoV-2 Spike pseudo virus and infectious SARS-CoV-2 virus on coated and uncoated surfaces, and the results of which evidenced that $\mathrm{TiO}_{2}$ - and $\mathrm{TiO}_{2}-\mathrm{Ag}$ coatings, compared to the uncoated control surfaces, effectively inactivated both SARS-CoV-2 pseudo 
and live viruses under ambient indoor light within hours. The authors indicated the potential of $\mathrm{TiO}_{2}$ Coatings as a tool in contribution to the control of SARS-CoV-2 transmission in public and health care settings. In this manuscript, the work has been well designed, clearly presented and concluded with relative adequate data.

Some minor comments are stated below:

1. There are a few different types of materials, e.g. metal-based, silicon-based, carbonbased, and polymers, that have been showing antiviral potentials. It would be good to briefly review the current literature on them and indicate the merit for investigating more on $\mathrm{TiO}_{2}$ - coatings than others.

Response: A formal review of literature would be lengthy. Hence we have focused on the tile based Ti02 coating.

1. The coating procedure was described in the methods section without further optimisation. Also, there are no further discussions on the validation and evaluation of the successful coatings on the surface. A series of surface characterisation techniques are therefore recommended, for example, ToF-SIMS and XPS to confirm the surface chemistries and their distributions after coating, and SEM to show the surface features and uniformity of the coating.

Response: Unfortunately these experiments are beyond the scope of this report but are important as the reviewer points out.

Competing Interests: none

Reviewer Report 17 March 2021

https://doi.org/10.21956/wellcomeopenres.18269.r43031

(C) 2021 van Zyl G. This is an open access peer review report distributed under the terms of the Creative Commons Attribution License, which permits unrestricted use, distribution, and reproduction in any medium, provided the original work is properly cited.

\section{Gert U. van Zyl}

${ }^{1}$ National Health Laboratory Service, Tygerberg Hospital, Cape Town, South Africa

2 Division of Medical Virology, Stellenbosch University, Stellenbosch, South Africa

Micochova et al. described the inactivation of SAR-CoV-2 on surfaces coated with titanium dioxide $\left(\mathrm{TiO}_{2}\right) \cdot \mathrm{TiO}_{2}$ is photocatalytic under ambient light, producing oxidative radicals that inactivate infectious agents. The inactivation of SARS-CoV-2 pseudotyped virus and live SARS-CoV-2 cultures were assessed on ceramic tiles coated with either $\mathrm{TiO}_{2}$ or $\mathrm{TiO}_{2}$-silver(Ag) by culturing viruses from these surface at different time intervals. The authors found that after 5 hours, no infective virus remained on the treated surface but it was still fully infectious on the untreated surface.

The manuscript adds valuable novel data and provides an apparently practicable solution to coating surfaces in hospitals, which would result in surface disinfection under ambient light. The manuscript is overall well-constructed, accessible and well-written. 
I have a few minor comments for improvement of overall clarity:

1. Please clarify how the photocatalytic activity of $\mathrm{TiO}_{2}$ is affected by natural vs incandescent vs fluorescent light bulbs?

2. Please describe the time intervals and procedure of sampling to assess infectivity in detail (were different spots sampled on the same surface?)

3. Please clarify the nature of the control surface used. The text referred to an "uncoated surface" which I assumed would be ceramic, but the figure refers to polystyrene (is the latter an appropriate control surface?)

4. Considering the potential of this surface coating: Please clarify a) how frequently the coating would have to be reapplied, b) what the cost of coating per square meter would be and c) how widely available $\mathrm{TiO}_{2}$ is for use as a spray for surface coating.

5. Please comment on the difference of respiratory droplets that contain mucous vs free cultured virus and how this may have affected the inactivation of viral particles.

Is the work clearly and accurately presented and does it cite the current literature? Yes

Is the study design appropriate and is the work technically sound?

Yes

Are sufficient details of methods and analysis provided to allow replication by others? Partly

If applicable, is the statistical analysis and its interpretation appropriate? Not applicable

Are all the source data underlying the results available to ensure full reproducibility? Partly

Are the conclusions drawn adequately supported by the results? Yes

Competing Interests: No competing interests were disclosed.

Reviewer Expertise: Diagnostic and clinical virology, HIV persistence, HIV drug resistance, viral epidemiology

I confirm that I have read this submission and believe that I have an appropriate level of expertise to confirm that it is of an acceptable scientific standard, however I have significant reservations, as outlined above.

Author Response 07 Sep 2021 
Ravindra Gupta, University of Cambridge, Cambridge, UK

Reviewer 1:

Micochova et al. described the inactivation of SAR-CoV-2 on surfaces coated with titanium dioxide $\left(\mathrm{TiO}_{2}\right)$. $\mathrm{TiO}_{2}$ is photocatalytic under ambient light, producing oxidative radicals that inactivate infectious agents. The inactivation of SARS-CoV-2 pseudotyped virus and live SARS-CoV-2 cultures were assessed on ceramic tiles coated with either $\mathrm{TiO}_{2}$ or $\mathrm{TiO}_{2}^{-}$ silver(Ag) by culturing viruses from these surface at different time intervals. The authors found that after 5 hours, no infective virus remained on the treated surface but it was still fully infectious on the untreated surface.

The manuscript adds valuable novel data and provides an apparently practicable solution to coating surfaces in hospitals, which would result in surface disinfection under ambient light. The manuscript is overall well-constructed, accessible and well-written.

\section{I have a few minor comments for improvement of overall clarity:}

1. Please clarify how the photocatalytic activity of $\mathrm{TiO}_{2}$ is affected by natural vs incandescent vs fluorescent light bulbs?

Response: Both natural (i.e. sunlight) and incandescent filament lamps approximate to black body radiators, albeit with different temperatures. The photocatalytic activity, which depends on the convolution of the incident light with the absorption spectrum of the $\mathrm{TiO}_{2}$, is therefore qualitatively the same for the two. The degree of activity (as measured e.g. by rate of inactivation of viruses) will simply depend on the actual irradiances -- to a first approximation linearly. Fluorescent lighting has a different spectral distribution. For a good estimate of the degree of photocatalytic activity, one can simply take the irradiance in the near UV-violet-blue spectral range and compare it with that of the natural or incandescent source.

1. Please describe the time intervals and procedure of sampling to assess infectivity in detail (were different spots sampled on the same surface?)

This has now been described in the methods in more detail

1. Please clarify the nature of the control surface used. The text referred to an "uncoated surface" which I assumed would be ceramic, but the figure refers to polystyrene (is the latter an appropriate control surface?)

Response: We used plastic as a control surface in the absence of an uncoated tile. We have now stated this in the limitations section.

1. Considering the potential of this surface coating: Please clarify a) how frequently the coating would have to be reapplied, b) what the cost of coating per square meter would be and c) how widely available $\mathrm{TiO}_{2}$ is for use as a spray for surface coating. Response: We have now specified in the paper that the coating would be re-applied every 6 12 months. The frequency depends on the adhesion of the coating and the degree of wear to which it is subjected. With no wear the coating lasts indefinitely. With moderate handtouching the coatings used in this work will typically last 6-12 months The cost is a few dollars per sq $\mathrm{m}$ and the coating is planned to be made widely available. The last two comments cannot really be put in the text as this is a changing area

1. Please comment on the difference of respiratory droplets that contain mucous vs free cultured virus and how this may have affected the inactivation of viral particles. 
Response: Mucous mainly contains mucin, a glycoprotein family, which would be photocatalytically oxidized to $\mathrm{CO} 2$ and $\mathrm{H} 2 \mathrm{O}$ by $\mathrm{TiO} 2$. Partially oxidized intermediates may themselves be radicals that would damage and inactivate the viruses. Without detailed mechanistic investigations it is difficult to predict whether the mucous accelerates or retards virus inactivation. The ultimate outcome is not expected to be different, however. We have now commented on this in the discussion and thank the reviewer for this point.

Competing Interests: No competing interests were disclosed. 